\title{
REVIEW
}

\section{Design of Intelligent Home Security Alarm System under STC89C51 Single Chip Microcomputer}

\section{Ruizheng Wang* Xuan Liu Xinhao Huang}

Artificial Intelligence College, North China University of Science and Technology, Tangshan, Hebei, 063000, China

\begin{tabular}{|c|c|}
\hline ARTICLE INFO & ABSTRACT \\
\hline Article history & \multirow{8}{*}{$\begin{array}{l}\text { In order to improve the security of home residence, this paper studies } \\
\text { and designs an intelligent home security alarm system, using STC } 89 \text { C } 51 \\
\text { single chip microcomputer as the main controller of the security system, } \\
\text { and real-time monitoring by controlling the human pyroelectric infrared } \\
\text { sensor and smoke sensor in the case of strangers invading the security } \\
\text { range and showing signs of fire. Once the abnormal situation is found, the } \\
\text { intelligent home security alarm system will start the acousto-optic alarm } \\
\text { prompted by the LED lamp and pass through the information processing } \\
\text { system of the GSM module. Send an abnormal text message to the user of } \\
\text { the security system at the first time face, and finally realize the purpose of } \\
\text { modern intelligent home security alarm. }\end{array}$} \\
\hline Received: 15 July 2020 & \\
\hline Accepted: 15 July 2020 & \\
\hline Published Online: 30 September 2020 & \\
\hline Keywords: & \\
\hline STC89C51 MCU & \\
\hline Intelligent & \\
\hline GSM & \\
\hline
\end{tabular}

Pyroelectric infrared

Security alarm system

\section{Introduction}

B ased on STC89C51 single chip microcomputer, this paper makes a research and analysis on the design of intelligent home security alarm system. The purpose of this intelligent system is to provide users with an intelligent home security alarm tool which is convenient to use, easy to operate and very practical. This intelligent security alarm system can send fire accident message to users in the first time of accident, especially in the initial stage of home fire.

\section{Brief Introduction of this Intelligent Home Security Alarm System}

An intelligent home security alarm system designed in this paper is very practical, safe and sensitive. The system mainly includes the following modules: pyroelectric infrared sensor, smoke sensor, GSM,alarm system, which achieves the basic functions of preventing theft, preventing fire and remote alarm and preventing accidental text messages. ${ }^{[1]} \mathrm{A}$ thermoluminescence infrared sensor in the module can identify the infrared rays emitted by the human body very well. When a stranger enters the range of the security system, the acousto-optic alarm system will run automatically. Through the information processing of the GSM module, the alarm system can be quickly sent to the users of the intelligent home security alarm system at the first time Text messages. A smoke sensor module can sensitively detect the smoke in the intelligent security system. ${ }^{[2]}$ When the fire appears and the smoke concentration

\footnotetext{
*Corresponding Author:

Ruizheng Wang,

Artificial Intelligence College, North China University of Science and Technology, No. 21 Bohai Avenue, Caofeidian District, Tangshan, Hebei, 063000, China;

Email:2840432403@qq.com
} 
reaches the set value of the security system, the smoke alarm module will automatically alarm, the GSM module will start immediately, and the fire emergency message will be sent to the system user immediately.

\section{A Study on the Main Modules of 2System}

\subsection{System Design Main Controller Analysis}

The main controller in this set of intelligent home security alarm system is STC89C51 single chip microcomputer, the advantage of STC89C51 single chip microcomputer is that it is a low-power, high-performance CMOS 8 bit micro controller, itself has $8 \mathrm{~K}$ of on-line programmable Flash memory, using high-density non-volatile memory technology research and manufacture, and industrial 80 C51 of all product instructions and pins can be fully compatible. ${ }^{[3]}$ An on-chip Flash receiver memory for online programming also applies to other regular programmers. Very smart 8 for single chip bit CPU and the programmable Flash, of online systems enable STC89C51 to be provided with more flexible and efficient coping schemes by many other embedded control applications.

The main function of the P0.3 pin in the STC89C51 single chip microcomputer in this set of intelligent home security alarm system is to control the alarm of the acousto-optic system. The main function of the P2.4 pin is to control the pyroelectric infrared sensor in the system. The main function of the P2.5 pin is to control the smoke sensor. The function of the P3.0 and the P3.1 pin is to connect the GSM module to realize the mutual transmission of information.

\subsection{Analysis of Pyroelectric Infrared Sensor in System Design}

The pyroelectric infrared sensor used in this intelligent home security alarm system is RE200B type of sensor. The RE200B sensor itself uses pyroelectric material polarization to detect infrared radiation with different temperature changes.

${ }^{[4]}$ The pyroelectric infrared sensor module generally includes three pins, the signal terminal, the power supply positive pole and the power supply negative pole, respectively, the pin at the P2.4 of the STC89C51 single chip microcomputer, the power supply and the contact ground. pyroelectric infrared sensor can sensitively detect whether there are strangers invading the security range of the system, by setting infrared probe in the monitoring position, the infrared radiation emitted by the human body can be converted into electrical signals, and its electrical signals are sent to the OUT port by the cooperation of amplifier circuit and comparison circuit. As soon as the OUT port outputs a high-level signal, the signal passes through the transistor 9013 and is converted to a low-level transmitter to STC89C51 MCU. STC89C51 pin at the P2.4C of the single chip microcomputer is high level state in normal operation. if the low level is detected, the high voltage is output through the P0.4 port, the alarm is controlled to emit the alarm sound of the buzzer, and the alarm indicator is lit at the same time. the GSM module will send an alarm message that detects a stranger invading the security system.

\subsection{Analysis of Smoke Sensor in System Design}

The smoke sensor adopts MQ-2 type of smoke sensor. The advantages of the MQ-2 type sensor are its high sensitivity, fast reaction speed, good stability, long service life and simple and convenient driving circuit. It is suitable for the detection of natural gas, various kinds of smoke, gas and gasoline and so on.

${ }^{[8]}$ The main component of the MQ-2 type smoke sensor is the LM393 voltage comparator, which adopts the principle of comparing the voltage of 2 feet with 3 feet. If the voltage of 2 feet is higher than that of 3 feet, 1 foot will automatically output low level; if the voltage of 2 feet is lower than that of 3 feet, 1 foot will automatically output high level. The voltage of three feet is obtained by dividing the voltage through a 9103 potentiometer of 10 $\mathrm{K}$, and the voltage of two feet will change with the change of smoke concentration in the range of MQ-2 detection. MQ-2 the smoke sensor is equal to a large resistance throughout the circuit, if the security range The smoke concentration inside increases, the blocking force of the MQ-2 will become smaller, the voltage output to 2 feet will naturally become larger, and the voltage of 2 feet will be larger than that of 3 feet. At this time, the LM393 voltage comparator will naturally send a low level to the STC89C51 MCU through 1 foot. ${ }^{[6,7]}$ The normal state of the P2.5 pin of the single chip microcomputer is a high voltage flat state. Once the low level is detected, the high voltage will be output through the output port of the P0.4, indicating the alarm sound of the buzzer issued by the control buzzer, and the alarm indicator will be lit, and the GSM module will send the detection of a stranger invading security system. Alarm messages within the system.

\subsection{Analysis GMS Module in System Design}

${ }^{[5]}$ The SIM900A module is applied in the design GMS the intelligent home security alarm system. The advantage of the SIM900A module is that its interface is very rich, the function is complete and the performance is powerful, and the applicability in many fields, such as smart home sys- 
tem, intelligent security, intelligent monitoring, on-board monitoring and intelligent alarm, is very high, which can completely meet the application requirements of the above system. circuit schematic diagram of the SIM900A module, as shown in figure 1 .

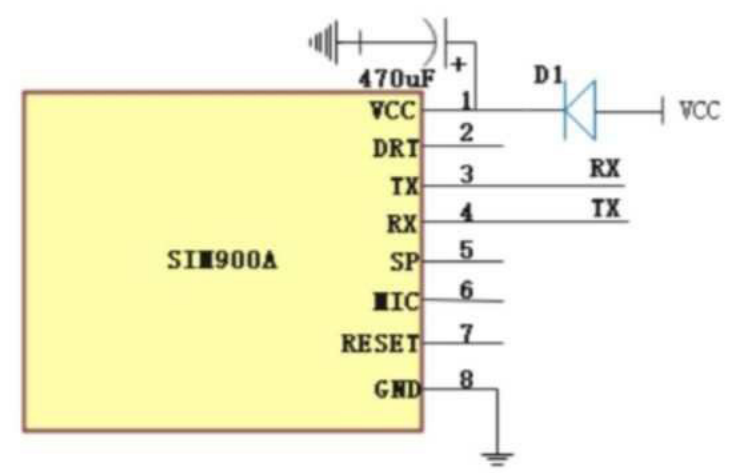

Figure 1. SIM900A Circuit diagram of the module

The pin 1 of the SIM900A module is connected to the LED lamp D1, and the main function is to indicate the operation of the GSM module. Pin 3 and pin 4 act on the transmission task of MCU pin P3.0 and P3.1, mainly to deal with alarm data, respectively.

\section{Concluding Remarks}

By deeply studying and analyzing the design of the intelligent home security alarm system under the action of STC89C51 single chip microcomputer, the function of the single chip microcomputer and the embedded application technology of the home security alarm system are successfully combined with the Internet of things technology. Exemption from family living around causing property, casualties, to provide people with a more intelligent, safe family living environment.

This design can be compatible with a large number STC89C51 control units under the design situation of single chip microcomputer, at the same time, it can combine these control units organically to form a whole set of intel- ligent control systems, make full use of STC89C51 single chip microcomputer, GSM the powerful function of the module to carry out systematic chip design for single chip microcomputer. STC89C51 single chip microcomputer has outstanding performance in its performance, excellent compatibility, low cost and strong practicability, and contributes to the stability of the whole security system. For the intelligent home security alarm system hardware, software design work carried out a lot of preparation work Through many experiments, we can overcome all kinds of difficulties and contradictions, and realize the design work of the intelligent home security alarm system.

\section{References}

[1] Jianfang Wen. Study on Home Intelligent Control System Based on AT89C51 Single Chip Microcomputer[J]. Electronic Production, 2019(09): 31-33.

[2] Qiaomei Ma. Design and Implementation of Fireproof and Anti-theft System for Dormitory Based on 51 Single Chip Microcomputer[J]. IT, 2018(03): 3944.

[3] Chaoyang Zhang. The Design of Gas Alarm Based on AT89C51 Single Chip Microcomputer[J]. Journal of Tonghua Normal University, 2017, 38(12): 7-10.

[4] Tianxiang Guo. New Concept 51 MCU C Language Course[M]. Beijing: Electronic Industry Press.

[5] Xiangbin Ye. Sensor and test technology [M]. Beijing: Defense Industry Press, 2007.

[6] Peng Chen. LonWorks villa smart home system introduction[J]. Low Voltage Appliances, 2008(14): 59-62.

[7] Wei Xu, Dean Zhao. Detection and control of dissolved oxygen in aquaculture[J]. Agricultural Mechanization Research, 2007(1): 74-76.

[8] Guangdi Li, Yuexiu Zhu, Xiushan Wang. Foundation of Single Chip Microcomputer (Revised Edition)[M]. Beijing: Beijing University of Aeronautics and Astronautics Press, 2005. 